\title{
Anthropocene: another academic invention?
}

\author{
Guido Visconti
}

Received: 21 March 2014/Accepted: 30 June 2014/Published online: 6 August 2014

(C) The Author(s) 2014. This article is published with open access at Springerlink.com

\begin{abstract}
The concept of Anthropocene is examined in its various aspects from the meaning of the word to its relevance in scientific research. The etymology of the word is not consistent with the meaning of other geologic epochs. The basic assumption that Anthropocene is shaping the planet is challenged considering that natural processes are and will be operating on the planet and have the potential to obliterate any trace left by the human activity. The reasons for the introduction of the epoch classification are also examined, and it is concluded that signals (different from geological ones) left by the present epoch will be of such precision to make useless any new classification. Finally, the political side of the new epoch is examined. Anthropocene is used as a basis to support the concept that nature is gone, and thus that there are no limits to its exploitation. On the other hand, to the Anthropocene are attributed all environmental changes, neglecting the fact that human is not the only factor affecting nature. Finally, it is noted that if one accepts the early Anthropocene hypothesis, only a fraction of the Holocene will remain.
\end{abstract}

Keywords Anthropocene - Geological history · Anthropic influence $\cdot$ Natural geological phenomena

\section{G. Visconti}

Dipartimento di Scienze Fisiche e Chimiche,

Università dell'Aquila, L'Aquila, Italy

\section{G. Visconti}

Center of Excellence on Integration of Remote Sensing

Techniques and Numerical Modeling for the Forecast of Severe

Weather (CETEMPS), Università dell'Aquila, L'Aquila, Italy

G. Visconti $(\square)$

CETEMPS c/o Department of Physics, University of L'Aquila, Coppito, L'Aquila 67010, Italy

e-mail: guido.visconti@aquila.infn.it

\section{Introduction}

The idea of Anthropocene was introduced by Crutzen and Stoermer (2000) (apparently Stoermer has used the term since early 1980s) in a paper in the Global Change Newsletter of the IGBP in May 2000. The idea was somewhat refined as a concept in a one-page article in Nature in 2002 (Crutzen 2002). Since then, the Anthropocene has been the subject of papers, meetings, ${ }^{1}$ and research and discussion at the scientific, political, and philosophical levels. The Anthropocene should define a new geologic epoch of the Quaternary Period and apparently should not change at all the substance of things, even less the political and economic perspectives of the present epoch.

The initial response to the idea came mainly from geology. Recently Autin and Holbrook (2012) observed that the main problem was that the proposed Anthropocene was not consistent with the practice of stratigraphy. After all, even if the manifestations of the human influence on the landscape are widespread, they are confined only to the first few meters of depth primarily to soils.

The stratigraphy issue seems to be the most important as stressed recently by Finney (2013) and Cohen et al. (2013). Finney raises a number of issues that must be addressed beside the stratigraphic one. They refer to the Anthropocene being a unit of Earth history or human history that is more like a projection into the future. This point stresses the fact that since the last millennium human observations (more and more complete and refined) will be used to study

\footnotetext{
${ }^{1}$ See the March 2014 issue of Rendiconti Lincei with the papers presented at the conference: Anthropocene: natural and man-made alterations of the Earth's fragile equilibrium held at the Accademia dei Lincei, Rome, November 26-27, 2012.
} 
the impact of the humans on the Earth's environment rather than a stratigraphic record that is minimal at best (Finney 2013). The other problem raised by Finney has to do with human-induced material bodies in the Anthropocene. These can be identified, for example, with a variety of specific symbols on large-scale topographic maps that are regularly updated. This argument is so strong that the same Finney is reported to affirm "Maybe the geologic time scale stops now" (http://geology.about.com/od/geotime_dating/ a/anthropocene.htm).

Finally, the most important observation is the fact that it is implicit in the Anthropocene terms that human dominated Earth system overwhelmed the natural Earth system. This would translate into the proposition that geological processes will not be relevant even in the future. The Anthropocene concept shows in this case its weakest point: an asteroid impact, for example, will obliterate any effects (if any) of the human-influenced environment. The concept ignores the fact that natural events in the Earth system can cancel human development. Geological epochs are dated when they have passed. This would be the first case in which the name it is assigned at the beginning on the presumption that it started. This is a very dangerous point because someone claims that the beginning of the Anthropocene follows within a couple of thousand years the beginning of the Holocene, determining in this way a direct transition, Pleistocene-Anthropocene.

The purpose of the present paper is to review critically the introduction of the Anthropocene and to show finally that the idea has been somewhat overstated. In the first part, a critique is made on the term itself (Anthropocene) that is apparently based on a misinterpretation of the word. This is also examined in view of the fact that chronology is now based on objective and measurable data as events occur. In the second part, we demonstrate that even the recent history of our planet is marked with violent events to show that Earth is still a very active planet subject to earthquakes, eruptions, and asteroid impacts whose consequences could easily mask any human geological signature. These catastrophic phenomena would be recorded accurately even when their effects are widespread. Finally the socio-economic implications of the Anthropocene are examined from two opposite point of view, those who support the idea that this epoch is just an anticipation of a bright future and those who view the new epoch as the latest capitalistic disguise.

\section{Anthropocene is the wrong word?}

We added a question mark to the original contribution by Moore (2013). This contribution is rather entertaining, but it may look a little like "fundamentalist green ideology" although it contains interesting reflections and cautionary statements. $^{2}$

That situation merits its own name, and so something like the Anthropocene makes sense. But we should use words cautiously. Words are powerful, magical, impossible to control. With a single misguided phrase, they can move a concept from one world into another, altering forever the landscape of our thinking. It's essential that we get this straight now.

Of the same spirit is the contribution by Jensen (2013).

All of this is crucial, because perpetrators of atrocity so often attempt to convince themselves and everyone else that what they are doing is natural or right. The word "Anthropocene" attempts to naturalize the murder of the planet by pretending the problem is "man," and not a specific type of man connected to this particular culture.

We will return to some of these ideas later and for the moment we would like to be a little more aseptic. In the papers mentioned in the introduction, the term Anthropocene is vaguely and insufficiently justified as in (Crutzen and Stoermer 2000).

Considering these and many other major and still growing impacts of human activities on earth and atmosphere, and at all, including global, scales, it seems to us more than appropriate to emphasize the central role of mankind in geology and ecology by proposing to use the term "Anthropocene" for the current geological epoch. The impacts of current human activities will continue over long periods.

The name was probably based on some kind of assonance with similar terms used to designate geologic epochs. Actually, the most entertaining explanation of these names is given by McPhee (1980).

From the Eocene, for example, which ended some thirty-eight million year ago, roughly three and a half percent have survived. Eocene means "dawn of the

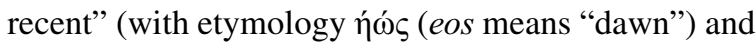
кavós (kainos, means "new")). ......From the Miocene ("moderately recent"), some fifteen per cent of molluscan species survive; from the Pliocene ("more recent"), the number approaches half....From the Pleistocene ("most recent") more than ninety percent

\footnotetext{
$\overline{2}$ We will "cut and paste" in the text citations taken from the references. The reason is that many of those references may be not familiar to the geoscience community especially when taken from web sites.
} 
of molluscan species live on. The name of the Cenozoic epochs was proposed by Charles Lyell whose Principles of Geology was the standard text through much of the nineteenth century. To settle problems here and there, the Oligocene ("but a little recent") was inserted in the list, and the Paleocene ("old recent") was sliced off the beginning.

As we can see it is not so straightforward to justify the term Anthropocene because each epoch is made of an ending (-cene indicating recent or new) and a changing root which refer to the "degree of new" of such period. A possible analog would name the Eocene "Mammalscene" to indicate the appearance of mammals in that epoch. Much more coherent is the suggestion made by Wilson (2007) to call the present Era, Eremozoiclonely/desolate life. This is consistent for example with Cenozoic era coming from кaıvó zoe "life". In the same wrong direction is the proposal made by (Langmuir and Broecker 2012) that again inconsistently propose Anthropozoic that is "human life"?

It is rather embarrassing that a "radical" text like Foster, Clark and York (2010) seems to accept without criticism the Anthropocene concept interpreting it in the wrong way.

Holocene literally means "new whole". It stands for the stable, interglacial geological epoch dating back 10,000 to 12,000 years in which civilization arose. Anthropocene in contrast means "New Human". It represents a new geological epoch in which humanity has become the main driver of rapid changes in the earth system.

First of all, there is a misinterpretation of the term because according to the previous discussion, Holocene means "entirely new" and only an unreasonable stretching may interpret Anthropocene as "new human". However, later on in the book the authors insist by introducing a further elaboration.

If the Holocene stood for new whole epoch in geological evolution, and the Anthropocene of the last two centuries stands for the new human epoch (as marked ironically by the crisis in the human domination of the planet) what we need to strive for is "Holoanthropocene-an epoch of the "New Whole Human" based on transcending the alienation of humanity and nature."

Apparently the way to solve problems is to introduce new terms.

Even the very conservative James Lovelock (2013), author of the fable of Gaia, manifests some doubt about the introduction of term Anthropocene.
I will follow Crutzen's example and appropriate Stoermer's word but with an even sharper definition. This is badly needed for otherwise this clear and useful term is in danger of losing resolution in the noisy background of vague academic niceties and amorphous thought about ecological sin.

But there is another more stringent reason to reject the introduction of Anthropocene and that is related to the requirements made by physicist, mathematics and chemists. Again McPhee.

taking note of all the nomenclatural inconsistencies -of time named for mountain ranges, time named for savage tribes, time named for a country here, a county there, an oblast in the Urals-have politely, gently, suggested that, in this one sense only, the time scale seems archaic, seems, if one may say so, out of date. Geology might be better sewed by a straightforward system of numbers. The reaction of geologists, by and large, has been to look upon this suggestion as if it had come over a bridge that exists between two cultures. A Continental geologist, in 1822, named eighty million years for the white cliffs of Dover, for the downs of Kent and Sussex, for the chalky ground of Cognac and Champagne. Related strata were spread out through Holland, Sweden, Denmark, Germany, and Poland. He called it Le Terrain Cretace.If that name was apt, his own was irresistible. He was JJ. d'Omalius d'Halloy.

Today geologic time is established by several methods, and the only reason to define a new epoch is to make it appealing to "poets and scientist" as Wilson suggests for his Eremozoic. The most equilibrate statement about the appeals to popular culture is made by Autin and Hoolbrook (2012).

If the prescribed conditions are met, then Anthropocene might be a useful time-stratigraphic term. In essence, it describes the disruptions driven by human activities. However, elevating terms that may become iconic in pop culture is not in itself sufficient evidence to amend formal stratigraphic practice. Science and society have much to gain from a clear understanding of how humans drive Earth-system processes instead of conducting an esoteric debate about stratigraphic nomenclature. Let the Anthropocene retain its rightful place as a focal point in the culture wars over the recognition and interpretation of environmental process.

Both McPhee (1980) and Gould (1987) show that one of the greatest achievements of geologic history is the 
discovery of "deep time", that the age of the Earth was orders of magnitude longer than what religion or popular culture believed. In this discovery, physicist of the time did not fare as well as to show that even the most exact of the sciences may have problems when used outside the right context (Lewontin 1990).

The first attempt to quantify the "deep time" by physicists ended with a gigantic flop. We refer here to the debate between geologists and Lord Kelvin about the definition of the age of the Earth. The most recent account given by England et al. (2007a, b) shows that Kelvin estimated the origin of the Earth between 24 and 400 million years based on the evaluation of the time it took for diffusive process to establish the measured temperature gradient within the Earth. This time was quite short of what geologists of the time estimated based on sedimentary rates and at the same time evolutionary theory that required a much longer scale. As England et al. (2007a) affirm.

The story of Kelvin and the age of the Earth are often told as a David and Goliath struggle with geologists playing the role of underdog, armed only with a slender sword of geological measurements, while Lord Kelvin bludgeoned them with the full force of prestige of mathematical physics.

At that time, John Perry (1895) pointed out that the arguments used by Kelvin were somewhat flawed, especially because he treated the Earth as a uniform rigid body with uniform properties. The main objection by Perry was that if there were an additional mechanism to transport heat from the interior, the age of the Earth would be much shorter. This is turn would require an additional heat source. The mechanism was later determined to be the convection in the mantle that is responsible among other things of continental drift. The additional source was radioactivity in the crust.

This story shows that interdisciplinarity is a very important key in Earth science research. As a matter of fact, the story is somewhat more complex as pointed out by Tipler (2013) and Stacey (2000) because even taking Perry's arguments as valid, the age of the sun as evaluated by Kelvin would be on the order of 100 million years. The hypothesis made by Kelvin on the generation of sun's energy was completely wrong because he could not know thermonuclear processes.

In conclusion, at the least at that time geologists and biologists (rather than physicists) had a central role in defining the age of the Earth. Today, however, it does not make any sense to define a new geologic epoch because the current civilization will leave extensive records of the characteristics of the epoch and of the environmental change it has made on the planet. Most of these proofs will be quantitative. Think only about geodetic measurements based on space-borne techniques. It is almost humoristic to read an account like Showstack (2013) reporting at the 2012 fall meeting of the American Geophysical Union where a section was dedicated to the Anthropocene. Some experts argued that the existence of Anthropocene could question some international laws. As an example, the Convention on the Law of the Sea includes the basic assumption that sea level will remain stable. If that changes (as ocean data documents), the 'building of the law' might 'literally fall into the water'. We all know this to be an obvious statement and even if this should be the case that does not depend on the introduction of a new epoch but simply because climate is changing and with it oceans are warming (thermally expanding) and glaciers are melting. Anthropocene has struck again and revealed its main purpose, to make headline in newspapers.

\section{The evolution of planet Earth}

The assumptions on which the definition of a new epoch are based seem to neglect that our planet continues its evolution and it will not be surprising that a million year from now this period of time will be remembered more on the basis of some geological long-term phenomena. The time interval interested by perturbations introduced by human activity constitutes such a negligible fraction of the age of the Earth that those perturbations cannot be compared to the consequences of long-term geological activity. To show the complexity of the interaction between anthropic activity and natural phenomena, we may illustrate how consequences of natural phenomena could be amplified by vulnerability of human infrastructure and vice versa: how sometimes human intervention may trigger devastating natural disaster. The most vivid example of the former process is the Fukushima incident where human interaction increased the damaging effects of the quake when the nuclear reactors were hit by the tsunami. The possibility that human activity could be the cause of large quakes has been raised by Lei et al. (2008), Ge et al. (2009) and Kerr and Stone (2009), who proposed that the 7.9 earthquake that struck Wenchuan in the Sichuan province in May 2008 was the consequence of the filling of the artificial Zipingpu Reservoir. Klose (2011) give a more recent assessment. More recently, "fracking" activity has been linked to the generation of earthquakes (Ellsworth 2013; van der Elst et al. 2013) and even the destructive earthquakes in Central Italy (Cartlidge 2014). A more general analysis correlating human activity and seismicity is given by Klose (2013).

The geologic activity does not know any sign of slowing down and in recent years, we had a glimpse of what earthquake and volcanic activity could produce. For 
example, recently a debate has developed whether the rate of big earthquakes has changed over the last period of time. An accurate statistical study by Shearer and Stark (2012) maintains that the rate has not changed so that the sequence observed after 2004 up to the Tohoku 2011 (Fukushima) episode may be not significant. Since the beginning of the twentieth century, seven quakes have hit 8.8 or higher on the Richter scale of which there was only one before 1950 . The next 50 years saw three earthquakes of large magnitudes of which the one in Chile in 1960 reached 9.5. However, the first decade of the present century has experienced three mega quakes above magnitude 8.8 in just 6 years time. It must be recognized that this may be just too short a period of time to draw any conclusions.

If we examine the geological history of the Earth, we find many examples of the influence of both volcanism and tectonic activity on climate and vice versa. The major evidence, however, of the disruptive force of natural events is the recorded mass extinctions of the past.

Extensive literature exists on the effect of the volcanic activity on climate from the most recent events (Pinatubo) to the distant past (for recent reviews see, Robock 2003; Robock and Oppenheimer 2003). The most recent disruptive eruption was Tambora in 1815. It released approximately $150 \mathrm{~km}^{3}$ of material containing 25-30 Mt of sulfur. In 1883, the Krakatoa eruption produced about $20 \mathrm{~km}^{3}$ of materials. One of the most powerful eruptions of the twentieth century (Pinatubo) was responsible for 5 cubic $\mathrm{km}$ of ejected material and about $5 \mathrm{Mt}$ of sulfur. Some 75.000 years ago the Toba catastrophe in Indonesia produced around $2,800 \mathrm{~km}^{3}$ of material, and some claim that has accelerated the last glaciation [Rampino and Self (1992, 1993a, 1993b)]. Many of these events leave noticeable traces in geologic strata (i.e. polar ice) as sulfate deposits. There is no reason to believe that such events may not occur again repeatedly in the future, and in some instance they could overwhelm any warming accumulated from greenhouse gases emissions and leave again noticeable traces in geological strata.

It is interesting to compare these data with the requirement envisaged for geoengineering the climate (Brovkin et al. 2009). A possible scenario would be the injection of an average $7 \mathrm{Mt}$ S/year staring from 2,070 to ending in 2,300 . The authors conclude that this is an acceptable figure considering that the annual global production of sulfur is about 10 times this amount that is the injections would perturb the natural sulfur cycle by $10 \%$ and, if maintained for 200 years, would be equivalent to 200 Pinatubo eruptions. Apparently, the "cure" would accentuate the disease and really affect the Anthropocene.

Huybers and Langmuir (2009) recently have provided a review of the complex interaction between deglaciation, volcanism, and $\mathrm{CO}_{2}$ content in the atmosphere. They have shown that $\mathrm{CO}_{2}$ production during deglaciation could accelerate the disruption of ice sheets while waning of the volcanic activity during the interglacial could reduce the carbon dioxide concentration and lead, or favor, the onset of an ice age. The conclusion is that carbon contained in the solid Earth may play an important role in determining the climate of our planet.

Earlier contributions by Berner (1999) and Ruddiman (2001) had already shown how tectonic activity might influence the global climate through the long-term carbon cycle. In particular, sea floor spreading could influence the carbon dioxide released into the atmosphere. This mechanism contains negative feedback processes that tend to compensate for the high $\mathrm{CO}_{2}$ release during periods of fast spreading or lower release during slow spreading. Models based on these ideas (Berner and Kothavala, 2001) have explained the evolution of the carbon cycle during Phanerozoic time. Another example of the recent influence of tectonics on climate change is the uplift of the Himalayas $(\sim 40 \mathrm{Ma})$ responsible for the glaciation of the Northern Hemisphere (De Conto (2009), Hay et al. (2002)). These examples support the idea that natural geological forcing is acting continuously on the planetary environment and remain the dominant forcing mechanisms.

The most impressive effects of natural processes are related to the mass extinctions with the most famous being the Cretaceous-Tertiary attributed to the impact of a meteorite with the Earth (Renne et al. 2013). The most important result for our discussion of the Renne et al. paper is that the asteroid impact (Chicxulub) is contemporary to the dinosaur extinction. This suggests that these large animals were already on the verge of extinction because of some other causes like abrupt and repeated climatic changes. The finding in the geological strata, was fundamental to clarify the timing of the impact and species extinction while the climatic data remain rather doubtful. This shows again that such catastrophic events are the main driver of the changing environment.

Wignall $(2001,2005)$ have attributed some mass extinction to the formation of the large igneous provinces (LIP), and for the end-Permian mass extinction there exist an extensive literature (Sahney and Benton 2008; Sobolev et al. 2011). LIPs are huge deposits of igneous rock, very frequent in the history of the Earth, and erupt gigantic volumes of volcanic flows in relatively short geologic times that may cover thousands of square kilometers and are hundreds of meters thick. Their effects on the environment are extremely important to the point of almost wiping out life. However, life recovered even from these episodes, showing that the Earth System is resilient to very great insults. (see Jones (2013) for an original parallel with Noah's Ark). Other examples of this kind are the recovery from the Paleocene-Eocene thermal maximum or the 
Snowball Earth episode. At the present time, human activity is influencing marginally the Earth system, and human-induced extinctions focus only on the big animals that appeal to humans, and no mention is made of the many animals and plants that are, instead, flourishing as a result of human impact. Again, this means that "Anthropocene is a term for human history and not for Earth history" (Finney personal communication).

These reported huge episodes in the Earth's history and in comparison the claim that mass extinction is taken as another possible connotation of the Anthropocene is rather weak. Pievani (2014) and Barnosky et al. (2011) have discussed in detail a hypotheses of the sixth mass extinction based on the possible evidence of an approaching tipping point for the biosphere (Barnosky et al. 2012). Kolbert (2014) has popularized the concept with an adequate dramatization. However, again there exist critics of this approach (Brook et al. 2013). Broecker (2010) has something very interesting to say about 'tipping points'.

What about the so called tipping points? It is currently fashionable in environmental circles to speak of irreversible thresholds that will be passed as the buildup of fossil fuel derived $\mathrm{CO}_{2}$ continues. Having been guilty of crying wolf, I am uncomfortable with this concept. Surely such tipping points may exist, but as we currently can only hint at what they might be, we can't predict at what level of the atmospheric $\mathrm{CO}_{2}$ buildup they might kick in.

This statement is contained in a chapter of the book entitled "The Anthropocene" in which only the first paragraph reports the usual definition. (Lewontin 2000), and Lewontin and Levins and (2007) discuss the tipping points in the realm of the three C's: catastrophe theory, chaos theory, and complexity theory.

The practitioners of catastrophe theory hoped that it would provide the explanation of changes in shape during the development of individual organisms, and of extinction of species, among other things, but there is currently no trace of this theory in biological practice. Indeed the externalities view has more recently triumphed in the claim that truly catastrophic events, meteor impacts, rather than mathematical catastrophes, have been responsible for a major part of species extinction. The fascination with the possibility of these external catastrophes has resulted in a complete neglect of the question of why every species goes extinct, with or without meteors.

It is very interesting here to note that not too much attention has been paid to the extinctions with no apparent cause. The problem of mass extinction was discussed by
Lewontin (2000) almost 15 years ago, and he rightly remarks.

The growing environmentalist movement to prevent alterations in the natural world that will be, at the best unpleasant and, at worst, catastrophic for human existence cannot proceed rationally under the false slogan "save the environment". "The environment" does not exist to be saved. The world inhabited by living organisms is constantly being changed and reconstructed by the activities of all those organisms, not just by human activity. Neither can the movement proceed under the banner "Stop the Extinctions!" Of all species that have ever existed 99.99 percent are extinct, and all species that currently exist will one day be extinct. Indeed all life on earth will one day be extinct, if no other reason than the sun will eventually expand and burn up the earth about two billion years from now. As life originated more than two billion of years ago, we can say with confidence that life on earth is half over. Although the average time from origination to extinction of species has fluctuated from era to era because of glacial ages, the drifting apart of continents, and occasional collision with meteors, it has not shown any long-term tendency to increase. Nor is there any factual basis for claims that species are in some sort of harmony or balance with each other or with the external world. We cannot prevent environmental changes or species extinction. It will take all the political force that can be marshaled just to influence the direction and rate of change of natural world. What we can do is to try and affect the rate of extinction and direction of environmental change in such a way as to make a decent life for human beings possible. What we cannot do is to keep things as they are.

More recently Lewontin and Levins (2007) somewhat detail these thoughts.

Every species of organism consumes the resources necessary for its life and, if unchecked by predation or competition, would undergo unlimited growth. Every organism produces waste products that are poisonous to itself. And why all this fuss about extinction? After all, 99.999 percent (he added another decimal digit!) of all species that have ever existed are already extinct and, ultimately, none will escape extinction. Time and chance happened to all. Moreover no species of vertebrate or flowering plant has become extinct in Britain in the last hundred years despite the toxic outpouring from the "dark satanic mills"; The Greeks had already completely 
deforested their land in Classical times and there hasn't been any prairie in North America for more than a century but that did not stop either the Greeks or the American to become dominant in their time.

These views appeared even earlier (Levins and Lewontin (1985) and correspond to the concept emphasized by Swyngedouw (2011).

Harvard biologists Levins and Lewontin, for example, argue too that Nature has been filled in by scientists with a particular set of universalizing meanings that ultimately de-politicize Nature and facilitate particular mobilizations of such "scientifically" constructed Nature In contrast, they insist that the biological world is inherently relationally constituted through contingent, historically produced, infinitely variable forms in which each part, human or non-human, organic or nonorganic, is intrinsically bound up with the wider relations that make up the whole. For Levins and Lewontin, therefore, no universalizing or foundational claim can be made about what Nature is, what it should be or where it should go.

Finally, there is an issue of the geological signal that should indicate the end of the Holocene and the beginning of the Anthropocene. The most illuminating discussion is reported in Gibbard and Walker (2013) where they argue that the most important signal from this point of view may be related to the changes in composition of the atmosphere measured in Antarctic ice deposits. However, these signals refer only to a limited area of our planet or show an impact that is delayed in time in different regions of the Earth. They conclude unequivocally.

There is no doubt that the term 'Anthropocene' has caught the popular imagination, as witnessed by the number of publications that have appeared in recent years that incorporate the term and, indeed, a new journal title Anthropocene is to be launched. But the question remains as to whether or not the utility of the term will be as an informal designation for the period of recent enhanced human activity, or whether it can be defined in a geological sense as formal timestratigraphic unit of the GTS (Geological Time Scale). For the various reasons expressed above, we feel that while the former may possibly be the case, the latter is currently unrealistic.

The preliminary conclusion is that Anthropocene advocates concentrate only on the changes induced by human activities neglecting the fact that natural processes are still the main driver of changes. This reinforces the argument that the new epoch may appeal more to media than to science. The term remains useless because future generations will have plenty of information to classify and characterize with great precision our epoch. It is also somewhat an academic exercise that tries to predict the future of the Earth based on what is happening in a very short period of time (the last century) with respect to the duration of the Holocene (11,000 years). Notice that, the previous epoch, Pleistocene, started 2.5 million years ago and that the duration of the geologic epochs is usually millions of year. Pleistocene is characterized by the ice ages with the huge changes that accompanied these global phenomena. It is almost ridiculous to call such a short period of time "Anthropocene epoch" giving it even a wrong name. In the following section, we will see that the human influence can probably be traced at the origin of the agriculture to the point that Anthropocene may coincide largely with the Holocene itself.

\section{The planet of no return}

This is the title of a contribution by Ellis (2011) to the volume Love your Monsters, (Shellenberger and Nordhaus 2011). This work is a hymn to the capacities of the human beings to survive in any situation however serious it can be.

Over the last several decades, a consensus has grown among scientists that humans have become the dominant ecological force on the planet. According to these scientists we are now living in the Anthropocene, a new geological epoch shaped by humans. While some have hailed this forward looking vision of the planet others have linked this view with the perennial concern that human civilization has exceeded the carrying capacity of Earth's natural system and may thus be fundamentally unsustainable. In this article, I argue that this latter notion rests upon a series of assumptions that are inconsistent with contemporary science on how human interact with ecosystems, as well as with most historical and archeological evidence.

Ellis's idea is that there are no planetary boundaries that can limit the human population growth and the economy. He envisages a good Anthropocene.

A good, or at least a better, Anthropocene is within our grasp. Creating that future will mean going beyond fears of transgressing natural limits and nostalgic hopes of returning to some pastoral or pristine era. Most of all, we must not see the Anthropocene as a crisis, but as the beginning of a new geological epoch ripe with human-directed opportunity. 
The main point in Ellis's argumentation is the agriculture and the availability of food. He mentions that agriculture has never failed human beings even through the most severe crisis, and also he claims that the end of the natural Earth being replaced by an artificial environment. The view on agriculture has been ridiculed by Dello-Russo (2013).

Ellis's view of the rise of agriculture is a classic myth that has been propagated by non-archaeologists for generations-the "better mousetrap" theory of agriculture. ${ }^{3}$ My own archaeological research suggests the opposite.

While on the same site McKibben (2013) maintains the following about overfishing.

He cites three papers in a footnote after his sentence about fisheries, but none contain numbers supporting his claim that they've disappeared; in fact, the latest FAO data indicates 260 million human beings employed in this phantom pursuit. If this seems picayune fact-checking, it in fact reflects a problem for his more fundamental argument, since it indicates that we're still mostly living off the fat of the incredibly fecund land we were born onto, even as we trash it.

Apparently, Ellis continues with his theory neglecting "facts" especially on the rate of climate change. It is not strange that he accepts without doubt the idea of an "early Anthropocene" (Ruddiman 2003). According to this theory, humans influenced the carbon cycle since the beginning of the agriculture at the onset of the Holocene about 8000 years ago. This conclusion has been challenged by Broecker and Stocker (2006), on the basis of a detailed analysis of the available geochemical data. If we accept Ruddiman's idea, then the transition Pleistocene-Holocene never happened and the original idea of the possible suppression of the next ice age would be a consequence as suggested by Archer (2009). However, based on the very detailed critics of Joos et al. (2004) the original Ruddiman idea was abandoned and reiterated (Ruddiman and Ellis 2009) based on the assumption of a drastic change in the per-capita land use change. Recently Stocker et al. (2011) have shown that using the most recent data both the original ideas or its update is untenable. However an almost contemporary paper (Ruddiman et al. (2011)) claims just the opposite confirming that this is a rather academic dispute. The conclusion, however, seems that humans are not

\footnotetext{
3 The better mousetrap theory seems to have originated by a proverb attributed to Emerson and the conclusion is that a higher quality product will dominate the market. Actually the reason for success are numerous and often not related to quality.
}

responsible for the late Holocene $\mathrm{CO}_{2}$ increase. If one accepts the early Anthropocene hypothesis, the Holocene would reduce to only 3000-4000 years and so that the transition would be Pleistocene-Anthropocene.

The point of view put forward by Ellis is completely consistent with the idea of geoengineering the planet. If natural Earth no longer exists, then humans are authorized to fix the thermostat of the planet (Hamilton 2012).

Crist $(2007,2013)$ gives a very articulate critique of the Anthropocene concept. Crist (2007) affirms.

The declaration that we live in the Anthropocene (to stay with this key example) has the ideological effect of discouraging deep questioning and dismissing even discussion of revolutionary action. Rather, we are indirectly advised, our fate is to live our days in the "Age of Modern Man," within which we must manage ourselves and the world as best we can. Further, the narrow and technical conception of climate change as "the problem" is beholden to the same fatalistic mind-set. The real problem-the industrial-consumer complex that is overhauling the world in an orgy of exploitation, overproduction, and waste-is treated with kid gloves, taken as given, and regarded as beyond the reaches of effective challenge.

The point of view here is completely different than the one expressed by Ellis and it is contained in the "industrialconsumer complex". Earlier in the same paper it is argued that the declaration that we have entered in the Anthropocene is "arrogant and premature" what should be unmasked as "humanity's domination over the planet or, at best, capitulating to fatalism". The most recent paper (Crist 2013) clarifies the conflict between two concepts. On one side is the inevitability of dominance of humankind over "nature", and the other that cultivates the idea to limit the anthropocentrism that inspires the introduction of the Anthropocene. This is a rather old problem that Crist dates back to the 1970s At that time Ehrlich and Holdren (1971) introduced the rather famous formula $\mathrm{I}=\mathrm{P} \times \mathrm{A} \times \mathrm{T}$, where $\mathrm{I}$ is for impact, $\mathrm{P}$ for population, $\mathrm{A}$ for Affluence, and $\mathrm{T}$ for Technological development. In some sense, this "formula" has since been used for investigating interactions between populations, economic growth, and technological change and may be too simple for a complex and non-linear concept like Anthropocene. However, even at that time when Ehrlich and Holdren pointed to (over) population as being the worst for the planet, Barry Commoner (1972) argued that technology is the dominant reason for environmental degradation in modern societies. This conflict of opinion is thus quite old, and the Anthropocene debate is just reviving it with some over confidence on the capacity of Homo sapiens (Steffen et al. 2007). 
Looking deeply into the evolution of the Anthropocene, future generations of $H$. sapiens will likely do all they can to prevent a new ice age by adding powerful artificial greenhouse gases into the atmosphere. Similarly any drops in $\mathrm{CO} 2$ levels to low concentrations, causing strong reductions in photosynthesis and agricultural productivity, might be combated by artificial releases of $\mathrm{CO} 2$, maybe from earlier $\mathrm{CO} 2$ sequestration. And likewise, far into the future, (why far and how far? N.d.A.) H. sapiens will deflect meteorites and asteroids before they could hit the Earth.

The fans of Anthropocene have the conviction that Homo sapiens can subdue the Earth and shape it according to his needs and this is coupled with the idea that nature is dead and gone as in Ellis.

Nature is gone. It was gone before you were born, before your parents were born, before the pilgrims arrived, before the pyramids were built. You are living on a used planet. If this bothers you, get over it. We now live in the Anthropocene-a geological epoch in which Earth's atmosphere, lithosphere and biosphere are shaped primarily by human forces. Yes, nature is still around-back-seat driving, annoying us with natural disasters from time to time, and everywhere present in the background-but definitely in no position to take the wheel. That's our job now. Don't blame nature for global warming, sea level rise, invasive species, mass extinctions, crop failures and poverty. That's our thing. Society needs to learn from recent scientific efforts to explain changes in greenhouse gases and the biosphere during the Anthropocene. Three lines of evidence demonstrate that we live on a planet reshaped by humans for thousands of years.

This is the planet of no return and has hilarious connections with Dr. Strangelove dreams. This concept is based on false assumptions like human forces shaping the lithosphere or the "annoyance" of natural disasters or the fact that humans have lifted nature responsibilities for mass extinctions: wait for the next comet impact!

\section{Conclusions}

The adoption of the Anthropocene concept has been discussed with the intent of showing that its introduction is useless. The main reason is that while geology has classified the different epochs of the past based on stratigraphy and very ingenious dating methods, this is no longer necessary now. Our civilization has overwhelming extensively documented physical signals that will give to future generations a precise and incontrovertible chronology of both natural and human-induced phenomena. The term itself is completely wrong both from the point of view of etymology and on the assumption that human civilization will leave traces (negligible?) on the geology of our planet. Even, the earthquakes attributed to human activity may not appear as a clear signal on record. Again, following Moore (2013).

Proud, solipsistic creatures that we are, we can convince ourselves that we are shaping Earth and, for a blink in time, it may be so. We have drawn perfect lines across the landscape, fence-rows parceling out property boundaries and delineating poisoned fields of corn and soybeans. But what we are sowing in those squares are the seeds of the destruction of our proud visions. How long will it take the whirlwinds to sweep them away, and along with them the chances of our children? And now, the very notion that humans have become the "deciders," the shapers of Earth, makes Earth guffaw in swirls of violence. If we are shaping anything at all, we are shaping climate chaos, and chaos in the ocean and on the land. If there is a voice in that whirlwind, it is not the voice of man.

Whirlwinds here stand for much serious phenomena like volcanic eruptions, landslides, asteroid impacts or LIP, even a new ice age, although this is one of the hottest topics in the Anthropocene debate.

The Anthropocene has a scientific side that is to find the golden spike, the geological signal that reveals its birthday, and a humanistic side that thinks this is another invention of academia or even worst a new way for the system to canonize its misdemeanor. As a matter of fact, even the most geological fundamentalists argue that the influence of man on the geology of the Earth is largely exaggerated considering the slowness of geological processes (plate tectonics) or the unpredictability (at the least limited predictability) of such events as asteroid impacts or LIP. On the other hand, the combination of unusual intense and unpredictable events and human actions may result in catastrophic consequences like the Sichuan earthquake or the Fukushima tsunami. In any of these instances, the traces left are still dominated by the natural event. Geologic processes may influence long-term climate change through the modulation of $\mathrm{CO}_{2}$ content through tectonic processes.

The final issue concerns the political impact of the Anthropocene. In recent times, a movement has developed that denies or declare dead the green movement and its achievements. The main idea is that "natural nature" is an obsolete concept because man has changed it to an almost complete artificial reality. In the words of Erle Ellis, one of 
the most outspoken fans of this concept, nature is gone. There is nothing wrong with exploiting all the resources of the planet and dominating it for human needs. Notice that this is an ancestral concept contained in Genesis: Everything that lives and moves about will be food for you. Just as I gave you the green plants, I now give you everything. And most of the people are prone to forget this statement. Jensen (2013) is very explicit in this regard.

The name also manifests the supreme narcissism that has characterized this culture from the beginning. Of course members of this culture would present their behavior as representing "man" as a whole. The other cultures have never really existed anyway, except as lesser breeds who are simply in the way of getting access to resources.

Using the term Anthropocene feeds into that narcissism. Gilgamesh destroyed a forest and made a name for himself. This culture destroys a planet and names a geologic age after itself. What a surprise.

It seems that Anthropocene far from filling a scientific need has become an element of pop culture (Autin and Holbrook 2012) that appeals to "poets and scientist" (Wilson 2007). The most equilibrate opinion on the matter was expressed by Richard Levins (personal communication).

The notion of the Anthropocene has double meaning. The appearance of the human species does represent a major shift in the history of the earth: unlike carnivores or omnivores we are productivores, making our own food, turning the inedible into edible, transforming the vegetation in order to do this. But since the origins of agriculture some 9,000 years ago we have been a succession of class societies, and each one has its own ways of relating with the rest of nature. So yes, there is a new epoch, but no it is not humankind in general but a succession of sub-epochs, types of class society.

The Anthropocene concept is a further proof that science adheres to the definition given by Lewontin et al. (1985), "is science what scientist do or is science made by scientists" which can be translated in many useful endeavors or a meaningless waste of time. Anthropocene most of the time is mentioned not as a scientific subject but rather as an epoch in which humanity either is subduing a no longer existing "natural nature" or exploiting a disappearing "natural nature". It depends on the political side but may not change the scientific perspective.

Acknowledgments I wish to thank Stan Finney who read the manuscript and provided very useful comments for its improvement.
Open Access This article is distributed under the terms of the Creative Commons Attribution License which permits any use, distribution, and reproduction in any medium, provided the original author(s) and the source are credited.

\section{References}

Archer D (2009) The Long Thaw, Princeton University Press, USA Autin WJ, Holbrook JM (2012) Is the Anthropocene and issue of stratigraphy or pop culture. GSA Today 22:60-61

Barnosky AD, Matzke N, Tomiya S, Wogan GOU, Swartz B, Quental TB, Marshall C, McGuire JL, Lindsey EL, Maguire KC, Mersey B, Ferrer EA (2011) Has the Earth's sixth mass extinction already arrived? Nature 471:51-57

Barnosky A, Hadly EA, Bascompte J, Berlow EL, Brown JH, Fortelius M, Getz WM, Harte J, Hastings A, Marquet PA, Martinez ND, Mooers A, Roopnarine P, Vermeij G, Williams JW, Gillespie R, Kitzes J, Marshall C, Matzke N, Mindell PD, Revilla E, Smith AB (2012) Approaching a state shift in Earth's biosphere. Nature 486:52-58

Berner RA (1999) The new look at the long term carbon cycle. GSA Today 9:1-6

Berner RA, Kothavala Z (2001) Geocarb III: a revised model of atmospheric $\mathrm{CO}_{2}$ over phanerozoinc time. Am J Sci 301:182204

Broecker WS (2010) The great ocean conveyor. Princeton University Press, USA

Broecker WS, Stocker TF (2006) The Holocene $\mathrm{CO}_{2}$ rise: anthropogenic or natural? EOS 87:27-29

Brook BW, Ellis EC, Perring MP, MacKay AW, Blomqvist L (2013) Does the terrestrial biosphere have planetary tipping points? Trends Ecol Evol 28:396-401

Brovkin V, Petoukhov V, Claussen M, Bauer E, Archer D, Jaeger C (2009) Geoegineering climate by stratospheric sulfur injections: earth system vulnerability to technological failure. Clim Change 92:243-259

Cartlidge E (2014) Human activity may have triggered fatal italian earthquake, panel says. Science 344:141

Cohen KM, Finney SC, Gibbar PL, Fan J (2013) The ICS international chronostratigraphic chart. Episodes 36:199-204

Commoner B (1972) The environmental cost of economic growth. In: Population, resources and the environment. Government Printing Office, Washington, DC, pp 339-363

Crist E (2007) Beyond the climate crisis: a critique of climate change discourse. Telos 141:29-55

Crist E (2013) On the poverty of our nomenclature. Environ Hum 3:129-147

Crutzen PJ (2002) Geology of mankind. Nature 415:23

Crutzen PJ, Stoermer EF (2000) The Anthropocene. Global Change Newsl 41:17-18

De Conto RM (2009) Plate tectonics and climate change. In: Gornitz $\mathrm{V}$ (ed) Encyclopedia of paleoclimatology and ancient environments, pp 784-797

Dello-Russo R (2013) Agriculture didn't plow under the hunters. http://Thebreakthrough.org/journal/debates/planet-of-no-returnabreakthroughdebate/agriculture-didnt-plow-under-the-hunters

Ehrlich PR, Holdren JP (1971) Impact of population growth. Science $171: 1212-1217$

Ellis E (2009) Stop to save the planet. http://www.wired.com/ wiredscience/2009/05/ftf-ellis-1/

Ellis E (2011) The planet of no return. In: Shellenberger M, Nordhaus $\mathrm{T}$ (eds) Love your monsters. Breakthrough Institute, USA 
Ellsworth WL (2013) Injection-induced earthquakes. Science 341:1225942

England PC et al (2007a) Kelvin and the age of the Earth. Am Sci 95:342

England PC et al (2007b) John Perry's neglected critique of Kelvin's age of the Earth: a missed opportunity in geodynamics. GSA Today 17:4-9

Finney SC (2013) The Anthropocene as a ratified unit in the ICS International Chronostratigraphic Chart: fundamental issue that must be addressed by the Task Group. Geological Society, Special Publications, London. doi:10.1144/SP395.9

Foster JB, Clark B, York R (2010) The ecological rift, capitalism's war on the Earth. Monthly Review Press, USA

Ge S, Liu M, Lu N, Godt JW, Luo G (2009) Did the Zipingpu Reservoir trigger the 2008 Wenchuan earthquake? Geophys Res Lett 36:L20315

Gibbard PL, Walker MJC (2013). The term 'Anthropocene' in the context of formal geological classification. In: Waters C, Zalasiewicz J, Williams M, Ellis M, Snelling A (eds) A stratigraphic basis for the Anthropocene. Geological Society, London, Special Publications. doi:10.1144/SP395

Gould SJ (1987) Time's arrow, time's cycle: myth and metaphor in the discovery of geologic time. Harvard University Press, USA

Hamilton C (2012) The philosophy of geoengineering. In: the atmospheric science and economics of climate engineering via aerosol injection. A contribution to the IMPLICC symposium the atmospheric science and economics of climate engineering via aerosol injection. Held at the Max Planck Institute for Chemistry, Mainz, Germany, 14-16 May

Hay WW, Soeding, E, De Conto RM, Wold CN (2002) The late Cenozoic uplift-climate change paradox. Int J Earth Sci 91:746-774

Huybers P, Langmuir C (2009) Feedback between deglaciation, volcanism, and atmospheric $\mathrm{CO}_{2}$, Earth Planet Sci Lett 286:479-481

Jensen D (2013) Age of the sociopath. Earth Island J, Spring 2013. http://www.earthisland.org/journal/index.php/eij/article/age_of_ the_sociopath/

Jones S (2013) The serpent's promise: the bible retold as science, Little, Brown

Joos FS, Gerber S, Prentice IC, Otto-Bleisner BL, Valdes P (2004) Transient simulations of holocene atmospheric carbon dioxide and terrestrial carbon since the last glacial maximum. Global Biogeochem Cyc 18:GB2002

Kerr RA, Stone R (2009) A human trigger for the great quake of Sichuan? Science 323:322

Klose CD (2011) Evidence for anthropogenic surface loading as trigger mechanism of the 2008 Wenchuan earthquake. Environ Earth Sci. doi:10.1007/s12665-011-1355-7

Klose CD (2013) Mechanical and statistical evidence of the causality of human-made mass shifts on the Earth's upper crust and the occurrence of earthquakes. J Seismolog. doi:10.1007/s10950-0129321-8

Kolbert E (2014) The sixth extinction: an unnatural history. Henry and Holt

Langmuir CH, Broecker W (2012) How to built a habitable planet. Princeton University Press, USA

Lei XL, Ma SL, Wen X, Su J, Du F (2008) Integrated analysis of stress and regional seismicity by surface loading - a case study of Zipingpu reservoir. Seismol Geol 30:1046-1064

Levins R, Lewontin R (1985) The dialectal biologists. Harvard University Press, USA

Lewontin R (1990) Fallen angels. NY Rev Books 37:1

Lewontin R (2000) The triple helix: gene, organism, and environment. Harvard University Press, USA
Lewontin R, Levins R (2007) Biology under the influence: dialectical essays on ecology, agriculture and health. Monthly Review Press, USA

Lewontin R, Rose S, Kamin LJ (1985) Not in our genes: biology Ideology and the human nature. Pantheon, USA

Lovelock J (2014) A rough ride to the future. Allen Lane, UK

McKibben B. http://thebreakthrough.org/journal/debates/planet-ofno-return-a-breakthrough-debate/erle-elliss-cheap-fantasy

McGuire B (2012) Waking the giant. Oxford, Oxford

McPhee J (1980) Basin and range. McGraw-Hill, New York

Moore KD, Anthropocene is the wrong word, Earth Island J, Spring 2013, http://www.earthisland.org/journal/index.php/eij/article/ anthropocene is the wrong word/

Perry J (1895) On the age of the earth. Nature 51:224-227

Pievani T (2014) The sixth mass extinction: anthropocene and the human impact on biodiversity, Rend Fis Acc Lincei 25:85-93

Rampino MR, Self S (1992) Volcanic winter and accelerated glaciation following the Toba super eruption. Nature 359:50-52

Rampino MR, Self S (1993a) Climate volcanism feedback and the Toba eruption of $\sim 74,000$ years ago. Quatern Res 40:269-280

Rampino MR, Self S (1993b) Bottleneck in human evolution and the Toba eruption. Science 262:1955

Renne PR et al (2013) Time scale of critical events around the Cretaceous- Paleogene boundary. Science 339:684-687

Robock A (2003) Volcanoes: role in climate. In: Holton J, Curry JA, Pyle J (eds) Encyclopedia of atmospheric sciences. Academic Press, London, pp 2494-2500

Robock A, Oppenheimer C (2003) (eds) Volcanism and the earth's atmosphere, geophysical monograph 139, AGU, Washington, DC, p 360

Ruddiman WF (2001) Earth's climate past and future, Freeman, UK

Ruddiman WF (2003) The anthropogenic greenhouse era began thousands of years ago. Clim Change 61:261-293

Ruddiman WF (2013) The Anthropocene. Annu Rev Earth Planet Sci 41:45-68

Ruddiman WF, Ellis EC (2009) Effect of per-capita land use changes on Holocene forest clearance and $\mathrm{CO}_{2}$ emissions. Quarter Sci Rev 28:3011-3015

Ruddiman WF, Kutzbach JE, Vavrus SJ (2011) Can natural or anthropogenic explanations of late-Holocene $\mathrm{CO}_{2}$ and $\mathrm{CH}_{4}$ increases be falsified? The Holocene 21:865-879

Sahney S, Benton MJ (2008) Recovery from the most profound mass extinction of all time. Proc R Soc B 275:759-765

Shearer PM, Stark PE (2012) Global risk of big earthquakes has not recently increased. Proc Natl Acad Sci 109:717-721

Shellenberger M, Nordhaus N (eds) (2011) Love your monsters, post environmentalism and the Anthropocene, Breakthrough Institute, USA

Showstack R (2013) Scientists debate whether the Anthropocene should be a new geological epoch. EOS 94:41-42

Sobolev SV et al (2011) Linking mantle plumes, large igneous provinces and environmental catastrophes. Nature 477:312-316

Stacey FD (2000) Kelvin's age of the Earth paradox revisited. J Geophys Res 105:13155

Steffen W, Crutzen P, McNeill J (2007) The Anthropocene: are humans now overwhelming the great forces of nature? Ambio 36 (8):614-621

Stocker BD, Strassmann K, Joos F (2011) Sensitivity of Holocene atmospheric $\mathrm{CO}_{2}$ and the modern carbon budget to early human land use: analyses with a process-based model. Biogeosciences 8:69-88

Swyngedouw E (2011) Whose environment? The end of nature, climate change and the process of post civilization. Ambiente Societade 14:69-87 
Tipler FJ (2013) Perry, Kelvin and the age of the sun. Eur Phys J 38:405

van der Elst NJ et al (2013) Enhanced remote earthquake triggering at fluid-Injection sites in the Midwestern United States. Science 341:164-167

Wignall PB (2001) Large igneous provinces and mass extinctions. Earth Sci Rev 53:1-33
Wignall PB (2005) The link between large igneous province eruptions and mass extinctions. Elements 1:293-297

Wilson EO (2007) The creation: an appeal to save life on Earth, Norton, New York 